\title{
Undergraduate Materials Research Initiative Funds 20 Projects, Announces 46 Honorable Mentions
}

Last fall, the Materials Research Society launched the Undergraduate Materials Research Initiative (UMRI) for which undergraduate students could apply for a $\$ 1,000$ grant to support their materialsrelated projects. Beth Stadler of the University of Minnesota and chair of the MRS Academic Affairs Committee said that the committee wanted to offer an undergraduate-level award similar to that offered to graduate students, but that undergraduate students involved in research would be unlikely to travel to MRS Meetings. She said that then president of MRS Robert Nemanich (North Carolina State University) encouraged the committee to propose an award that teaches undergraduate students that MRS is all about materials research.

The committee designed a research funding program for fiscal year 1999 to introduce undergraduate students to the excitement of discovery through research in materials science and engineering. Under the program, each undergraduate awardee would receive a grant for the cost of a moderate research project of no more than $\$ 750$ plus an additional award of $\$ 250$ payable directly to each of the undergraduate researchers upon completion of the project.

Stadler, along with committee members Omar Manesreh (U.S. Air Force, New Mexico) and Susan Lord (University of San Diego), decided to make the process as educational as the research. They formatted a program announcement after typical announcements of U.S. government agencies which they then posted on the MRS website on November 1, 1998. Stadler said, "We required the same procedures as standard proposals, from description of ideas right down to institution signatures. It seemed like a lot of work for such small grants, so we were thrilled when 125 very high quality proposals were submitted in January 1999 . The proposals were submitted by undergraduate researchers from 16 countries, and half of them were beyond a doubt worth funding. However, our bud- get only allowed the top 20 to be funded, so another 46 were given Honorable Mention."

MRS Past-President Nemanich said, "One of our goals last year was to emphasize activities which contribute to building a professional identity of MRS as a Society which we belong to throughout our careers. We implemented this Initiative to encourage undergraduates to become involved in materials research."

The grants were awarded in February. The final step for the grant recipients is to write a final report in the format of a professional article such as a proceedings, letter, or journal article. The students are encouraged to submit their reports to peer-reviewed journals.

On behalf of the Academic Affairs Committee, Stadler said, "We would like to thank everyone who submitted proposals and congratulate you on a job well done! These exceptional undergraduates, along with their advisors and institutions, are listed in this article."

\section{Undergraduate Materials Research Initiative Grant Recipients}

Crystal Bailey

Effects of Boundary Conditions on Simulated Molecular Beam Epitaxy

Crystal Growth

University of Arkansas

Paul Thibado, Advisor

Michael Beam

Deposition of Tungsten Carbide

Contings for Tribological Applications

Using Laser Ablation of Microparticles Method

University of Texas at Austin

Michael F. Becker, Advisor

Lisa Bishop

Low Temperature Magnet-Optical

Kerr Effect Project

University of Colorado

Z. Celinski, Advisor

Pierre Bourque

Fractography of Tungsten and

Platinum Wire under Single- and

Multivariable Loading

Washington State University

M. Grant Norton, Advisor

Luis Cruz Rivera

Morphological Studies of Ni Foil

Electrodes

Praire View A\&M University

Thomas N. Fogarty, Advisor

Janet Cuy

Characterization of Tooth Enamel:
Correlation in Structure, Chemistry, and Mechanical Properties Johns Hopkins University Timothy Weihs, Advisor

Ed Gozkowski, III Single Crystal Growth of $\mathrm{Pb}\left(\mathrm{Mg}_{1 / 3}\right.$ $\left.\mathrm{Nb}_{2 / 3}\right) \mathrm{O}_{3}-35 \mathrm{~mol}^{2} \mathrm{PbTiO}_{3}$ (PMN-35 PT) from Polycrystal Precursors Lehigh University Martin Harmer, Advisor

Alison Jackson

Characterization of Grain Size and Composition Effects on the Imprint Behavior of Piezoelectric THUNDER Actuators

Clemson University

Robert W. Schwartz, Advisor

William Junek

Chernical Bath Deposition of Thin

Film Photozoltaic Solar Cells

Florida Institute of Technology

Ryne Raffaelle, Advisor

Kasi Kiehlbaugh

Development of Chemical Reaction

Mechanisms for Gas Phase Wafer

Cleaning

University of Arizona

Anthony Muscat, Advisor

Donnacha Lowney

Sub-Gap Absorption Spectra and

Physical Characterization of Semicon- ductor Materials Using Photoncoustic Spectroscopy and Synchrotron X-Ray Topography Techniques

Dublin City University Patrick J. McNally, Advisor

Danielle Minnich

Synthesis, Characterization and Properties of PGA-co-PLA/PEO PGA-co-PLA Tri-Block Copolymers:

A Potential Drug Carrier

University of Akron

Stephanie Lopina, Advisor

Ben Pelletier

Artificial Aging of PMMA Bone

Cement

University of California at Berkeley

Lisa Pruitt Advisor

Joel Persson

Improving the Electrical Behavior of $\mathrm{Ni}$ YSZ Cermet Anodes by Optimizing YSZ Particle Size and Particle Size Distribution for Use in Anode Supported Solid Oxide Fuel Cells (SOFCs) University of Utah

Anil Virkar, Advisor

Heather Powell

Evolution of Porosity and Equilibrium Distribution of Common Fluids in Hydroxyapatite Aggregates: Application to Replacement Bone

Bowling Green State University

John R. Farver, Advisor
Claudia Ritter

Structural and Time-Resolved Scamning Probe Microscopy Study of

Heterogeneous Amalgamated Systems on a Nanometer Scale

Humboldt University, Berlin

Klaus Rademann, Advisor

Erica Robertson

Growth of Diamond-Titanium Composite Films for Field Emission

North Carolina State University

Robert J. Nemanich, Advisor

Jens Schumacher

Epitaxial Growth of Oxides on Silicon Johannes Gutenberg Univ. Mainz

Juan Carlos Martinez, Advisor

Per Slycke

Investigation of Imposed Loyer-by-

Lonyer Growth of Complex Oxide Thin

Films with Pulsed Laser Deposition

University of Twente

Ir. D.H.A. Blank, Advisor

Kris Suthers

Temperature-Induced Fracture of Chert and Some Anthropological

Applications

Oberlin College

Lynn Fisher, Advisor 


\section{Undergraduate Materials Research Initiative Honorable Mentions}

Daniel Aubertine

The Structure of $2 D$ Pt Clusters

Studied with X-Ray Photoelectron Spectroscopy, Scanning Tunneling Microscopy, and Fourier Transform Infrared Spectroscopy Measurements of Adsorbed $\mathrm{CO}$

Case Western Reserve University Gary Chottiner, Advisor

\section{Brant Blomberg}

Simulation and Experimental Determination of Resistance Changes in Integrated Circuit Interconnects

University of Michigan

John Sanchez, Jr. , Advisor

Eamon Briggs

Hall Measurements on Erbium- and

Oxygen-Doped Silicon

Colby College

Shelby F. Nelson, Advisor

James Camp

Stabilizing Hyaluronic Acid Films

through Chemical Crosslinking

University of Texas at Austin

Christine Schmidt, Advisor

Mary Chapman

New Second-Order Nonlinear Optical Materials via Crystal Engineering of Acentric Diamond-Type Metal-

Organic Frameworks

Brandeis University

Wenbin Lin, Advisor

\section{Adam Cohen}

Redox Cycling and Molecular Conduction in Hg-SAM SAM-Hg Junctions Harvard University

George Whitesides, Advisor

\section{Brian Crozier}

Adhesion Strength of Lead Zirconate

Titanate (PZT) Thin Films

Determined Using Nanoindentation

Washington State University

David F. Bahr, Advisor

\section{Thomas Daniel}

Testing a Surface Barrier Model to Describe the Luminescent Properties of Colloidal Semiconductors

Mercer University

Dale E. Moore, Advisor

Thomas Davidsmeier

Canted Dipolar Many Body Systems

Illinois Wesleyan University

Narendra Jaggi, Advisor

\section{Matthew Davis}

Preparation of AlN/TiN Solid

Solution Via Pyrolysis of Mixed-Metal

Organometallic Precursors

King's College

Frederick C. Sauls, Advisor

Filipa de Vasconcelos

Integration of Polymer Light-Emitting

Diodes with Amorphous Silicon a-Si:H

Thin Film Transistors for Large Area

Display Applications

Instituto de Engenharia de Sistemas e Computadores (INESC), Portugal Joao Pedro Conde, Advisor
Paul El-Diery

Electromigration

Lehigh University

G.S. Cargill III, Advisor

Luis Gardea

Magnetic Tape Micro Tensile Tester

University of the Pacific

Brian L.Weick, Advisor

Dayna Grajewski

Investigation of the Nucleation of

Cadmium Telluride on Silicon

University of Mllinois at Chicago

S. Sivananthan, Advisor

Massimo Groppi

Computer Simulation and TEM

Analysis of Primary Crystallization in

Amorphous Alloys

Università di Torino, Italy

Livio Battezzati, Advisor

April Hixson

Effect of Valence Cation Size on

Fragile Glass Formation

Containerless Research, Inc.

Richard Weber, Advisor

Sharon Hogue

The Preparation of Novel Zeolite Films vin Laser Ablation

University of Texas at Dallas

Kenneth J. Balkus, Jr. , Advisor

Gregory Horvath

Construction of New Silver-Hydroxy

Stilbazole-Indium Tin Oxide

Photovoltaic Cell

Fordham University

John J. McMahon, Advisor

\section{Kevin Hwang}

Using Optics to Create a Better

Colloidal Crystal

Rice University

Vicki Colvin, Advisor

Jennifer Lewis

Study of the Physical Properties of the Alkali Vanadate Glass System Related to Atomic Structure

Coe College

Steve Feller, Advisor

Christopher Love

Well-defined Monodisperse Polydimethylsiloxane-Functionalized

Ruthenium (II) Tris (Bipyridine)

Complexes with a Tunable

Architecture for Oxygen Sensors

University of Virginia

Cassandra Frasier, Advisor

Olexander Lozovski

Optical Study of Polysaccharides

National Academy of Sciences of

Ukraine

Ostap Getsko, Advisor

Vera Margaretha

Study on the Growth Mechanism of

$\mathrm{SnO}_{2}$ Thin Film Deposited by

Chemical Vapor Deposition Method at

Low Temperature

Bandung Institute of Technology,

Indonesia

Wilson W. Wenas, Advisor
Kustov Maxim

Optical Study of Polysaccharides

National Academy of Sciences of

Ukraine

Ostap Getsko, Advisor

\section{Brian McAdams}

Grain Growth and Orientation in

Freestanding Aluminum Thin Films

Lehigh University

Richard P. Vinci, Advisor

Evan McCarney

An In Situ Study of the Bio-

degradation of Polyhydroxybutyrate

Using Atomic Force Microscopy

James Madison University

Brian H. Augustine, Advisor

\section{Melanie Morris}

Molecularly Engineered Layered Materials

American University

Kelley J. Donaghy, Advisor

Christopher Murray

The Glass Transition in Freely

Standing Polystyrene Films

University of Guelph, Canada

John Dutcher, Advisor

Michael Oye

Plasma Enhanced Chemical-Vapor

Deposition of 1,3,5-tris (tri-

flouromethyl) Benzene

University of California at Santa

Barbara

Eray S. Aydil, Advisor

\section{John Richardson}

The Effect of Particle Proximity and Reactant Transport on the Rate of Reaction Between Calcium Hydroxide and Fly Ash from Coal Combustion Tennessee Technological University Joseph J. Biernacki, Advisor

\section{Matteo Rinaldo}

Excitons and Impurities in Semiconductor Heterostructures: A Study in Fractional-Dimensional Space Worcester Polytechnic Institute Lok C. Lew Yan Voon, Advisor

\section{Steven Robertson}

The Synthesis and Characterization of

Anisotropic Gold Nanocrystals

Rice University

Vicki Colvin, Advisor

\section{Jodie Rochemont}

Bioactive Delivery Systems for the

Slow Release of Antibiotics:

Incorporation of $\mathrm{Ag}+$ ions into the

Nanoporous Titanium Oxide Coatings

Queen's University, Canada

M. Shirkhanzadeh, Advisor

\section{Rachel Rosen}

Fabrication and Characterization of

Aligned Nanotube/Polymer Composites

University of North Carolina at

Chapel Hill

Otto Zhou, Advisor

\section{Leslie Sarikas}

Pore Size Effects on the Flourescence
Spectra of Sol-Gel Matrices

Wheaton College

Laura Muller, Advisor

Gregory Schmett

Synthesis and Studies of Red-Emitting Organic Electroluminescent Materials University of Nevada, Las Vegas

Linda S. Sapochak, Advisor

Joshua Schmidt

Intercalation of the Layered Solid Acid

$\mathrm{HCa}_{2} \mathrm{NbTa}_{2} \mathrm{O}_{10}$ by Organic Amines

Reed College

Margret J. Geselbracht, Advisor

Agris Spiss

Recording of Holographic Optical

Elements in Amorphous

Semiconductor Photoresists

Institute of Solid State Physics,

Latvia

Janis Teteris, Advisor

Jason Stauth

Hall Measurements on Erbium- and

Oxygen-Doped Silicon

Colby College

Shelby F. Nelson, Advisor

\section{Michele Sumstine}

Investigation of In-doping of Cadmium

Sulfide During Growth by Molecular

Beam Epitaxy

University of Ilinois at Chicago

S. Sivananthan, Advisor

Brian Tiberio

High Temperature Compression Creep Behavior of $\mathrm{Ti}_{3} \mathrm{SiC}_{2}$

Drexel University

Michael Barsoum, Advisor

Nancy Washton

Synthesis and Studies of Red-Emitting Organic Electroluminescent Materials University of Nevada, Las Vegas

Linda S. Sapochak, Advisor

Simon Werner

Preparation of Collagen Dispersions

Widener University

Jerry Jaffia, Advisor

Fransisca Widyawardhani

Study on Factors Affecting the Luminescence Intensity and Efficiency of

Light Emission in Erbium-Doped

Silicon

Bandung Institute of Technology,

Indonesia

Wilson W. Wenas, Advisor

David Wilson

Strength and Formation of Passive

Films on Stainless Steel

Washington State University

David F. Bahr, Advisor

Angela Yuliana

Energy-Gap Calculation of Semiconductor Quantum Dots

Bandung Institute of Technology, Indonesia

Wilson W. Wenas, Advisor 